\title{
Food consumption patterns among children and adolescents and their correlation with overweight/obesity in Egypt: A cross-sectional study
}

\author{
Ayoub Al Jawaldeh ${ }^{1, A, D-F}$, Israa Ahmed Radwann ${ }^{2, B, C, F}$, Dina Rady ${ }^{2, B, C, F}$, Sara El Moshy ${ }^{2, B, C, F}$, Nermeen Abu Bakr ${ }^{2, B, C, F}$, \\ Marwa Magdy Saad Abbass ${ }^{2, A-F}$ \\ ${ }^{1}$ Institute of Nutritional Sciences, University of Vienna, Vienna, Austria \\ ${ }^{2}$ Department of Oral Biology, Faculty of Dentistry, Cairo University, Egypt \\ A - research concept and design; B - collection and/or assembly of data; C - data analysis and interpretation; \\ $D$ - writing the article; $E$ - critical revision of the article; $F$ - final approval of the article
}

Pielęgniarstwo iZdrowie Publiczne, ISSN 2082-9876 (print), ISSN 2451-1870 (online)

Piel Zdr Publ. 2020;10(3):149-157

Address for correspondence

Marwa Magdy Saad Abbass

E-mail: marwa.magdy@dentistry.cu.edu.eg

Funding sources

None declared

Conflict of interest

None declared

\section{Acknowledgements}

We would like to acknowledge the support and technical guidance of the Nutrition Unit at the World Health Organization office for the Eastern Mediterranean region.

Received on 0ctober 7, 2019 Reviewed on November 20, 2019 Accepted on February 10, 2020
Cite as

Al Jawaldeh A, Radwan IA, Rady D, El Moshy S, Abu Bakr N, Abbass MMS. Food consumption patterns among children and adolescents and their correlation with overweight/ obesity in Egypt: A cross-sectional study. Piel Zdr Publ. 2020;10(3):149-157. doi:10.17219/pzp/118081

DOI

10.17219/pzp/118081

Copyright

○ 2020 by Wroclaw Medical University

This is an article distributed under the terms of the

Creative Commons Attribution 3.0 Unported License

(https://creativecommons.org/licenses/by/3.0/)

\begin{abstract}
Background. Overweight and obesity have become epidemic diseases in Egypt. The first step to combat overweight and obesity is to study their immediate and underlying causes.

Objectives. To evaluate the prevalence of overweight/obesity among Egyptian children and adolescents in correlation to food consumption patterns and other risk factors.

Material and methods. This study was conducted in 369 children and adolescents, age ranging 3-18 years. Sociodemographic data and food consumption patterns were recorded using a food frequency questionnaire. Body mass index was calculated and the World Health Organization (WHO) age- and gender-percentile charts were used to determine overweight and obesity.

Results. We found that 147 (39\%) of the children and adolescents studied were overweight or obese. Age was inversely correlated to overweight/obesity prevalence and male gender was positively correlated. The highest rate of overweight/obesity was at the age of 3-4 years among boys. Parental education levels and socioeconomic status revealed no correlation with overweight/obesity. Carbonated soft drinks were the only dietary element positively correlated (Spearman's rho $=0.129 ; p=0.017$ ). After adjusting the effect of age and gender; carbohydrates, eggs, sugar (either added by the consumer to drinks and food or eaten on their own), crackers, junk food, chocolate, carbonated soft drinks and juices influenced overweight/obesity among children and adolescents $(p<0.05)$.

Conclusions. High percentages of overweight/obesity have been reported among Egyptian children and adolescents. Prompt action needs to be taken to prohibit unhealthy food items including carbonated soft drinks, crackers, juices and chocolates in schools as well as to advocate for increasing taxes on them.
\end{abstract}

Key words: obesity, overweight, children and adolescents, food consumption 


\section{Introduction}

Overweight and obesity present significant challenges to human health, especially in developing countries. Both contribute to an estimated 4 million deaths (7.1\% of all deaths) across the global population. ${ }^{1}$ In 2017, an estimated 38.3 million (5.6\%) children under 5 years of age were overweight. ${ }^{2}$ An even higher percentage (9.3\%) has been reported among children under age 5 in the Eastern Mediterranean Region (EMR). Considerable levels of overweight children under 5 years of age have been recorded in Libya (22.4\%), followed by Syria (17.9\%), then Lebanon (16.7\%) and Egypt (15.7\%). Moreover, the rate of overweight and obesity among children and adolescents aged 5-19 has risen dramatically worldwide ${ }^{3}$ from just $4 \%$ in 1975 to over $18 \%$ in 2016. Similarly, EMR children and adolescents recorded a higher incidence of overweight and obesity in 2016: 27.3\%. Percentages reach $42.4 \%$ in Kuwait, followed by $38.7 \%$ in Qatar, $36.7 \%$ in Egypt, and $35 \%$ in the Kingdom of Saudi Arabia and the United Arab Emirates. ${ }^{4}$ Overweight and obesity during childhood is associated with an increased risk of overweight/obesity in adulthood $^{5}$ and concomitant cardiometabolic diseases. ${ }^{6}$

Changes in food consumption patterns during the past decades have had a great impact on the increase in nutrition-related chronic diseases. ${ }^{7}$ Children nowadays eat too many refined grains, sugary foods and drinks; and on the other hand, too little fruit, vegetables, legumes and whole grains. About 1/3 (30.3\%) of school-aged children do not consume any fruit daily, while $43.7 \%$ consume soda every day. ${ }^{8}$ However, the per capita consumption of fruits and vegetables in Egypt is relatively satisfactory (102.6 and $193.65 \mathrm{~kg} /$ year, respectively) $)^{9}$ as compared to the recommendation for daily intake of fruit and vegetables, which is about $150 \mathrm{~kg} /$ year. $^{10}$ The rate of carbonated drink consumption every day among school students is very high: $54.9 \%{ }^{11}$

In Egypt, the majority of studies that focus on the predominance of overweight and obesity among children and adolescents lack investigations of the frequency of different food items in those children's diets. The aim of this study is to highlight food consumption patterns for 14 food items and their correlation with the incidence of overweight and obesity among children and adolescents in Egypt. Surveying dietary habits is essential in assessing nutrition programs as well as inputting policies related to food subsidies and taxes, nutrition intervention programs and nutrition education to restrain and control nutrition-related diseases.

\section{Material and methods}

This study was carried out following the framework of the Ethics Committee, Faculty of Dentistry, Cairo University, Egypt (No. 171217). This cross-sectional study was conducted among a convenience sample of children and adolescents who were treated from November 15, 2017 until January 13, 2018 in outpatient clinics at the Faculty of Dentistry at Cairo University, and in 2 private early-childcare nurseries at Nasr City and El Maadi (Egypt). The participants were children and adolescents aged 3-18 years old; both genders were included.

Written consent to participate in the study was obtained from the children's parents or guardians. Verbal consent was obtained from the adolescents in addition to written consent from their parents/guardians.

The sample size was set at 369 using the simple formula described by Daniel and Cross ${ }^{12}$ : Egypt's population of children and adolescents was predetermined as 50,000,000, and the prevalence of overweight in this population was estimated as $36.7 \%$ in accordance with WHO data. ${ }^{4}$

\section{Data collection and grouping}

Data was obtained through a questionnaire investigating age, gender, address, the level and type of the child's education (none, nursery or school), the number of family members, parental professions and education levels (low: primary school or illiterate; moderate: diploma or high school education; or high: university education). The assessment of the children's and adolescents' dietary habits for 14 dietary elements (Table 1) was performed using a food frequency questionnaire. Questions were filled out by the authors on the basis of parents' answers on behalf of their children and the adolescents' own answers.The frequencies used in the questionnaire were once per month; $1-2$ times per week; $3-4$ times per week; 5-6 times per week; once per day; $2-3$ times per day; 4-5 times per day; and 6 or more times per day. To facilitate the comparison and statistical analysis, these frequencies were merged into the 3 frequencies displayed: $\leq 2$ times/week; 3-6 times/week; 1-6 times/day. Body weights were measured using a Beurer scale (Ulm, Germany) with the participants wearing clothes but without shoes. In accordance with the WHO 1995 guidelines, standing heights were measured to the nearest $0.1 \mathrm{~cm}$ utilizing a stadiometer. From the measured heights and weights, body mass indices (BMIs) were calculated. The obtained BMI values were plotted on the WHO percentile body mass index (BMI/age) charts for boys and girls. ${ }^{13}$

The children and adolescents were divided into 4 categories based on their BMI percentiles: the underweight group $\left(<5^{\text {th }}\right.$ percentile); the normal group $\left(\geq 5^{\text {th }}-<85^{\text {th }}\right.$ percentile); the overweight group $\left(\geq 85^{\text {th }}-<95^{\text {th }}\right.$ percentile); and the obese group ( $\geq 95^{\text {th }}$ percentile). ${ }^{14}$ Moreover, the participants were grouped according to their age into group I (3-4 years old); group II (5-9 years old) and group III (10-18 years old). Depending on the children's education type (none, private, governmental or experimental), their parents' occupations and education levels (low/medium/ high), their addresses and the health centers where they 
Table 1. Description of the dietary elements investigated

\begin{tabular}{|c|c|}
\hline Dietary item & Full description \\
\hline Carbohydrates & bread, rice, macaroni, mahshi, potatoes and sweet potatoes \\
\hline Eggs & - \\
\hline Fruits/vegetables & fresh or cooked \\
\hline Milk and milk products & milk, yogurt and cheese (all types) (butter is not included) \\
\hline Grains & fava beans, wheat and peas \\
\hline Sugar & sugar added to drinks (hot or cold) and food or eaten on its own \\
\hline Jam, molasses and honey & jam, molasses, honey and halvah \\
\hline Candies & hard, sticky, lollipops \\
\hline Crackers & biscuits and chips \\
\hline Junk food & $\begin{array}{l}\text { any of the following food items prepared outside home (ready-to-eat food): burgers, pizza, fried potatoes/chicken/ } \\
\text { falafel), fava beans, koshary, shawarma sandwiches }\end{array}$ \\
\hline Chocolate & bars, chocolate cakes \\
\hline Soda & sweetened carbonated drinks \\
\hline Juices & fresh, canned and citric \\
\hline Caffeinated drinks & tea, coffee, instant-coffee sachets (commonly known in Egypt as 3 in 1) \\
\hline
\end{tabular}

received their treatments (governmental or private), they were assorted into low, middle and high socioeconomic subgroups. ${ }^{15}$

\section{Statistical analysis}

The data was statistically described in terms of frequencies (number of cases) and percentages. In comparing more than 2 groups the Kruskal-Wallis test was used, while in comparing 2 groups the Mann-Whitney $U$ test was used. Correlations between various variables were assessed using Spearman's rank correlation equation $(r h o)$. Multivariate logistic regression analysis was used to test for the preferential effect of each foodstuff on obesity; $p$-values of less than 0.05 were considered statistically significant. All the statistical calculations were done using SPSS software, v. 22 for Microsoft Windows (IBM Corp., Armonk, USA).

\section{Results}

\section{Population profile}

The participants were categorized into underweight (7.4\%), normal (52.8\%), overweight (14.9\%) and obese (24.9\%) according to their BMI percentiles. The statistical analysis was performed after excluding the underweight subjects. The overweight and obese groups were merged into a single group: The overweight/obese group comprised 39.8\% (Table 2).

In the entire study cohort, $30.7 \%$ of the participants were aged 3-4 years, $42.1 \%$ were $5-9$ years and $27.2 \%$ of participants were aged $10-18$ years.

The highest percentages of children and adolescents consumed carbohydrates (94.4\%), fruits/vegetables (45.9\%), milk and milk products (72.2\%), sugar, either added by the consumer to drinks and food or eaten on its own (65.2\%), candies (61.4\%), crackers (58.8\%) and juices (citric, fresh, canned) (44.2\%) 1-6 times per day. Eggs, jams, junk food, chocolates, carbonated soft drinks and caffeinated drinks were consumed 2 times per week or less $(51.5 \%, 55 \%$, $62.3 \%, 82.7 \%, 52.9 \%, 64.9 \%, 44.7 \%, 75.7 \%$, 53.5\%, respectively). Equal percentages of children and adolescents consumed grains 1-6 times per day or 2 times per week or less $(46.2 \%)$. It is important to note that a high percentage of children and adolescents consumed caffeinated drinks 1-6 times per day (43.9\%) (Table 2).

Descriptive data regarding gender, parental education and socioeconomic status (SES) within each age group is displayed in (Table 3).

\section{Correlations between overweight/obesity and different risk factors}

As Table 4 shows, the highest percentage of overweight/obese children was recorded among children aged 3-4 years (51.4\%), while the lowest percentage was recorded among adolescents aged $10-18$ years (31.2\%). The difference between the groups was statistically significant $(p=0.005)$. Age was inversely correlated with the participants' BMI percentiles (Spearman's rho $=-0.154$; $p=0.004)$.

The percentage of overweight/obesity among male children and adolescents was $52.4 \%$, while among girls it was $36.2 \%$. The difference between the two groups was statistically significant $(p=0.003)$. Male gender was significantly correlated with the increased BMI percentiles (Spearman's $r h o=-0.162 ; p=0.003$ ).

The highest percentage of overweight/obese participants was recorded in the low SES group (48.3\%), while the lowest percentage was recorded in the middle SES (36.5\%). 
Table 2. Descriptive analysis of categorical variables $(N=342)$

\begin{tabular}{|c|c|c|c|}
\hline Parameter & \multicolumn{3}{|c|}{$\begin{array}{c}\text { Categories } \\
n(\%)\end{array}$} \\
\hline \multirow{2}{*}{ Age [years] } & $\mathrm{Al}(3-4)$ & All (5-9) & AllI (10-18) \\
\hline & $105(30.7)$ & $144(42.1)$ & $93(27.2)$ \\
\hline \multirow{2}{*}{ Gender } & bo & \multicolumn{2}{|c|}{ girls } \\
\hline & 143 & \multicolumn{2}{|c|}{199 (58.2) } \\
\hline \multirow{2}{*}{ BMI } & nor & \multicolumn{2}{|c|}{ overweight and obese } \\
\hline & $19(5$ & \multicolumn{2}{|c|}{$147(39.8)$} \\
\hline \multirow{2}{*}{ SES } & low & middle & high \\
\hline & $151(44.2)$ & $115(33.6)$ & $76(22.2)$ \\
\hline \multirow{2}{*}{ Parental level of education } & low & medium & high \\
\hline & $67(19.6)$ & $110(32.2)$ & $165(48.2)$ \\
\hline Food consumption & $\leq 2$ times/week & 3-6 times/week & $1-6$ times/day \\
\hline Carbohydrates & $8(2.3)$ & $11(3.2)$ & $323(94.4)$ \\
\hline Eggs & $176(51.5)$ & $79(23.1)$ & $87(25.4)$ \\
\hline Fruits/vegetables & $84(24.6)$ & $101(29.5)$ & $157(45.9)$ \\
\hline Milk and milk products & $53(15.5)$ & $42(12.3)$ & $247(72.2)$ \\
\hline Grains & $158(46.2)$ & $26(7.6)$ & $158(46.2$ \\
\hline Sugar & $71(20.8)$ & $48(14.0)$ & $223(65.2)$ \\
\hline Jam, molasses and honey & $213(62.3)$ & $47(13.7)$ & $82(24.0)$ \\
\hline Candies & $101(29.5)$ & $31(9.1)$ & $210(61.4)$ \\
\hline Crackers & $114(33.3)$ & $27(7.9)$ & $201(58.8)$ \\
\hline Junk food & $283(82.7)$ & $15(4.4)$ & $44(12.9)$ \\
\hline Chocolate & $181(52.9)$ & $52(15.2)$ & 109 (31.9) \\
\hline Soda & $222(64.9)$ & $40(11.7)$ & $80(23.4)$ \\
\hline Juices & $133(38.9)$ & $58(17.0)$ & $151(44.2)$ \\
\hline Caffeinated drinks & $183(53.5)$ & $9(2.6)$ & $150(43.9)$ \\
\hline
\end{tabular}

Table 3. Descriptive analysis of gender, parental education and socioeconomic status within each age group $(N=342)$

\begin{tabular}{|c|c|c|c|c|c|c|c|c|c|c|c|}
\hline \multirow{3}{*}{\multicolumn{2}{|c|}{$\begin{array}{l}\text { Parameter } \\
\text { and categories }\end{array}$}} & \multicolumn{10}{|c|}{$n(\%)$} \\
\hline & & \multicolumn{2}{|c|}{ gender } & \multicolumn{3}{|c|}{ parental education } & \multicolumn{3}{|c|}{ socioeconomic status } & \multicolumn{2}{|c|}{ body mass index } \\
\hline & & boys & girls & low & medium & high & low & middle & high & normal & $\begin{array}{c}\text { overweight/ } \\
\text { obese }\end{array}$ \\
\hline \multirow{3}{*}{$\begin{array}{l}\text { Age } \\
\text { [years] }\end{array}$} & $\mathrm{Al}(3-4)$ & $48(45.7)$ & $57(54.3)$ & $12(11.4)$ & $25(23.8)$ & $68(64.8)$ & $27(25.8)$ & $20(19)$ & $58(55.2)$ & $51(48.6)$ & $54(51.4)$ \\
\hline & All (5-9) & $67(46.5)$ & $77(53.5)$ & $39(27.1)$ & $61(42.4)$ & $44(30.5)$ & $89(61.8)$ & $44(30.6)$ & $11(7.6)$ & $80(55.6)$ & $64(44.4)$ \\
\hline & Alll (10-18) & $28(30.1)$ & $65(69.9)$ & $64(68.8)$ & $29(31.2)$ & $64(68.8)$ & $29(31.2)$ & $64(68.8)$ & $29(31.2)$ & $64(68.8)$ & $29(31.2)$ \\
\hline
\end{tabular}

Regarding parental education, the highest percentage of overweight/obesity was among participants whose parents' education levels were medium (49\%), while the lowest percentage was among children and adolescents with high parental education levels (38.8\%). The differences between these groups were statistically insignificant $(p \geq$ $0.05)$. Socioeconomic status and parental education levels were not correlated with the participants' BMI percentiles $(p \geq 0.05)$.

The highest percentages of overweight/obese children and adolescents were recorded among those who consumed carbohydrates, eggs, crackers, jams, chocolate, carbonated soft drinks and juices 1-6 times per day; in children and adolescents who consumed junk food and sugar (either added by the consumer to drinks and food or eaten on its own) 3-6 times per week as well as in children and adolescents who consumed fruits/vegetables, milk and milk products, grains, candies and caffeinated drinks twice a week or less. Comparisons between the groups in all the dietary elements were statistically insignificant except for carbonated soft drinks ( $p=0.017)$. Moreover, no correlation was found between any dietary elements and BMI percentiles in children and adolescents except for carbonated soft drinks, where a positive correlation was found (Spearman's $r h o=0.129$; $p=0.017$ ). 
Table 4. Correlations between BMI categories and different risk factors $(N=342)$

\begin{tabular}{|c|c|c|c|c|c|c|c|c|c|c|}
\hline \multirow{3}{*}{\multicolumn{2}{|c|}{ Parameter and categories }} & \multicolumn{2}{|c|}{$n(\%)$} & \multirow{3}{*}{$\begin{array}{c}\text { M-W test } \\
p \text {-value }\end{array}$} & \multicolumn{2}{|c|}{ Correlation } & \multicolumn{4}{|c|}{ Logistic regression } \\
\hline & & \multirow{2}{*}{ normal } & \multirow{2}{*}{$\begin{array}{l}\text { overweight/ } \\
\text { obese }\end{array}$} & & \multirow{2}{*}{ rho } & \multirow{2}{*}{$p$-value } & \multirow{2}{*}{$p$-value } & \multirow{2}{*}{ OR } & \multicolumn{2}{|c|}{$95 \% \mathrm{Cl}$ for OR } \\
\hline & & & & & & & & & lower & upper \\
\hline \multirow{3}{*}{ Age [years] } & $\mathrm{Al}(3-4)$ & 51 (48.6) & $54(51.4)$ & \multirow{3}{*}{$0.005^{*}$} & \multirow{3}{*}{-0.154} & \multirow{3}{*}{$0.004^{*}$} & \multirow{3}{*}{-} & \multirow{3}{*}{-} & \multirow{3}{*}{-} & \multirow{3}{*}{-} \\
\hline & All (5-9) & $80(55.6)$ & $64(44.4)$ & & & & & & & \\
\hline & Alll (10-18) & $64(68.8)$ & $29(31.2)$ & & & & & & & \\
\hline \multirow{2}{*}{ Gender } & boys & $68(47.6)$ & 75 (52.4) & (ดคว & & & & & & \\
\hline & girls & $127(63.8)$ & $72(36.2)$ & $0.003^{\circ}$ & -0.102 & $0.003^{n}$ & - & - & - & - \\
\hline & low & $78(51.7)$ & $73(48.3)$ & & & & & & & \\
\hline SES & middle & $73(63.5)$ & $42(36.5)$ & 0.175 & -0.073 & 0.176 & - & - & - & - \\
\hline & high & $44(57.9)$ & $32(42.1)$ & & & & & & & \\
\hline & low & $38(56.7)$ & $29(43.3)$ & & & & & & & \\
\hline $\begin{array}{l}\text { Parental level of } \\
\text { education }\end{array}$ & medium & $56(50.9)$ & $54(49.1)$ & 0.244 & -0.063 & 0.245 & - & - & - & - \\
\hline & high & $101(61.2)$ & $64(38.8)$ & & & & & & & \\
\hline Dietary habits & & & & & & & & & & \\
\hline & $\leq 2$ times/week & $5(62.5)$ & $3(37.5)$ & & & & & & & \\
\hline Carbohydrates & 3-6 times/week & $9(81.8)$ & $2(18.2)$ & 0.138 & 0.080 & 0.138 & $<0.001^{*}$ & 1.625 & 1.243 & 2.125 \\
\hline & 1-6 times/day & $181(56.0)$ & $142(44.0)$ & & & & & & & \\
\hline & $\leq 2$ times/week & $108(61.4)$ & 68 (38.6) & & & & & & & \\
\hline Eggs & 3-6 times/week & $44(55.7)$ & $35(44.3)$ & 0.065 & 0.100 & 0.065 & $0.012^{*}$ & 1.299 & 1.058 & 1.594 \\
\hline & 1-6 times/day & $43(49.4)$ & $44(50.6)$ & & & & & & & \\
\hline & $\leq 2$ times/week & $40(47.6)$ & $44(52.4)$ & & & & & & & \\
\hline Fruits/vegetables & 3-6 times/week & $59(58.4)$ & $42(41.6)$ & 0.062 & -0.101 & 0.062 & 0.581 & 1.065 & 0.852 & 1.330 \\
\hline & 1-6 times/day & $96(61.1)$ & $61(38.9)$ & & & & & & & \\
\hline & $\leq 2$ times/week & $25(47.2)$ & $28(52.8)$ & & & & & & & \\
\hline $\begin{array}{l}\text { Milk and milk } \\
\text { products }\end{array}$ & 3-6 times/week & $25(59.5)$ & $17(40.5)$ & 0.232 & -0.065 & 0.233 & 0.294 & 1.119 & 0.907 & 1.381 \\
\hline & 1-6 times/day & $145(58.7)$ & $102(41.3)$ & & & & & & & \\
\hline & $\leq 2$ times/week & $85(53.8)$ & $73(46.2)$ & & & & & & & \\
\hline Grains & 3-6 times/week & $18(69.2)$ & $8(30.8)$ & 0.427 & -0.043 & 0.428 & 0.162 & 1.169 & 0.939 & 1.454 \\
\hline & 1-6 times/day & $92(58.2)$ & $66(41.8)$ & & & & & & & \\
\hline & $\leq 2$ times/week & $43(60.6)$ & $28(39.4)$ & & & & & & & \\
\hline Sugar & 3-6 times/week & $25(52.1)$ & $23(47.9)$ & 0.824 & 0.012 & 0.824 & $0.010^{*}$ & 1.332 & 1.070 & 1.659 \\
\hline & $1-6$ times/day & $127(57.0)$ & $96(43.0)$ & & & & & & & \\
\hline & $\leq 2$ times/week & 119 (55.9) & $94(44.1)$ & & & & & & & \\
\hline $\begin{array}{l}\text { Jam, molasses and } \\
\text { honey }\end{array}$ & 3-6 times/week & $32(68.1)$ & 15 (31.9) & 0.857 & -0.010 & 0.857 & 0.232 & 1.141 & 0.919 & 1.416 \\
\hline & 1-6 times/day & $44(53.7)$ & $38(46.3)$ & & & & & & & \\
\hline & $\leq 2$ times/week & $53(52.5)$ & 48 (47.5) & & & & & & & \\
\hline Candies & 3-6 times/week & $22(71.0)$ & $9(29.0)$ & 0.668 & -0.023 & 0.669 & 0.090 & 1.205 & 0.971 & 1.495 \\
\hline & 1-6 times/day & $120(57.1)$ & $90(42.9)$ & & & & & & & \\
\hline & $\leq 2$ times/week & $70(61.4)$ & $44(38.6)$ & & & & & & & \\
\hline Crackers & 3-6 times/week & $16(59.3)$ & $11(40.7)$ & 0.209 & 0.068 & 0.209 & $0.010^{*}$ & 1.283 & 1.060 & 1.552 \\
\hline & 1-6 times/day & $109(54.2)$ & $92(45.8)$ & & & & & & & \\
\hline & $\leq 2$ times/week & $168(59.4)$ & 115 (40.6) & & & & & & & \\
\hline Junk food & 3-6 times/week & $6(40.0)$ & $9(60.0)$ & 0.062 & 0.101 & 0.062 & $0.003^{*}$ & 1.561 & 1.167 & 2.088 \\
\hline & $1-6$ times/day & $21(47.7)$ & $23(52.3)$ & & & & & & & \\
\hline
\end{tabular}

The correlation coefficient rho ranges from -1 to +1 where: 1 = perfect positive correlation; $0=$ no correlation; $-1=$ perfect negative (inverse) correlation

* Statistical significance ( $p$-value $<0.05)$.

M-W test - Mann-Whitney $U$ test; OR - odds ratio; $\mathrm{Cl}$ - confidence interval. 
Table 4 cont. Correlations between BMl categories and different risk factors $(N=342)$

\begin{tabular}{|c|c|c|c|c|c|c|c|c|c|c|}
\hline \multirow{3}{*}{\multicolumn{2}{|c|}{ Parameter and categories }} & \multicolumn{2}{|c|}{$n(\%)$} & \multirow{3}{*}{$\begin{array}{c}\mathrm{M} \text {-W test } \\
p \text {-value }\end{array}$} & \multicolumn{2}{|c|}{ Correlation } & \multicolumn{4}{|c|}{ Logistic regression } \\
\hline & & \multirow{2}{*}{ normal } & \multirow{2}{*}{$\begin{array}{l}\text { overweight/ } \\
\text { obese }\end{array}$} & & \multirow{2}{*}{ rho } & \multirow{2}{*}{$p$-value } & \multirow{2}{*}{$p$-value } & \multirow{2}{*}{ OR } & \multicolumn{2}{|c|}{$95 \% \mathrm{Cl}$ for $\mathrm{OR}$} \\
\hline & & & & & & & & & lower & upper \\
\hline \multirow{3}{*}{ Chocolate } & $\leq 2$ times/week & $110(60.8)$ & $71(39.2)$ & \multirow{3}{*}{0.115} & \multirow{3}{*}{0.085} & \multirow{3}{*}{0.116} & \multirow{3}{*}{$0.007^{*}$} & \multirow{3}{*}{1.335} & \multirow{3}{*}{1.084} & \multirow{3}{*}{1.645} \\
\hline & 3-6 times/week & $29(55.8)$ & $23(44.2)$ & & & & & & & \\
\hline & 1-6 times/day & $56(51.4)$ & $53(48.6)$ & & & & & & & \\
\hline \multirow{3}{*}{ Carbonated drinks } & $\leq 2$ times/week & $137(61.7)$ & $85(38.3)$ & \multirow{3}{*}{$0.017^{*}$} & \multirow{3}{*}{0.129} & \multirow{3}{*}{$0.017^{*}$} & \multirow{3}{*}{$0.001^{*}$} & \multirow{3}{*}{1.464} & \multirow{3}{*}{1.169} & \multirow{3}{*}{1.834} \\
\hline & 3-6 times/week & $20(50.0)$ & $20(50.0)$ & & & & & & & \\
\hline & 1-6 times/day & $38(47.5)$ & $42(52.5)$ & & & & & & & \\
\hline \multirow{3}{*}{ Juices } & $\leq 2$ times/week & $76(57.1)$ & $57(42.9)$ & \multirow{3}{*}{0.778} & \multirow{3}{*}{0.015} & \multirow{3}{*}{0.779} & \multirow{3}{*}{$0.045^{*}$} & \multirow{3}{*}{1.240} & \multirow{3}{*}{1.005} & \multirow{3}{*}{1.529} \\
\hline & 3-6 times/week & $35(60.3)$ & $23(39.7)$ & & & & & & & \\
\hline & 1-6 times/day & $84(55.6)$ & $67(44.4)$ & & & & & & & \\
\hline & $\leq 2$ times/week & $100(54.6)$ & $83(45.4)$ & & & & & & & \\
\hline Caffeinated drinks & 3-6 times/week & $7(77.8)$ & $2(22.2)$ & 0.438 & -0.042 & 0.438 & 0.262 & 1.123 & 0.917 & 1.377 \\
\hline & 1-6 times/day & $88(58.7)$ & $62(41.3)$ & & & & & & & \\
\hline
\end{tabular}

The correlation coefficient $r$ ho ranges from -1 to +1 where: 1 = perfect positive correlation; $0=$ no correlation; $-1=$ perfect negative (inverse) correlation.

* Statistical significance ( $p$-value $<0.05)$.

M-W test - Mann-Whitney $U$ test; OR - odds ratio; $\mathrm{Cl}$ - confidence interval

Interestingly, eggs, junk food and fruits/vegetables were close to significant levels ( $p=0.065$ for eggs, and 0.062 for junk food and fruits/vegetables). Eggs and junk food were positively correlated (Spearman's $r h o=0.1 ; p=0.065$ and 0.062 , respectively) while fruits and vegetables were inversely correlated (Spearman's rho $=-0.1 ; p=0.062$ ).

After adjusting for the effects of age and gender, the following items were found to have an impact on overweight/obesity among children and adolescents: carbohydrates, eggs, sugar (either added by the consumer to drinks and food or eaten on its own), crackers, junk food, chocolate, carbonated soft drinks and juices $(p=0.001$, $p=0.012, p=0.010, p=0.010, p=0.003, p=0.007, p=0.001$, $p=0.045$, respectively) (Table 4 ).

\section{Discussion}

Many factors are involved in the development of overweight and obesity, including genetics, environment, lifestyle and food consumption patterns. ${ }^{16}$ The present study investigated the predominance of overweight/obesity among Egyptian children and adolescents in correlation to food consumption patterns and other factors (i.e. age, gender, socioeconomic status and parental education levels).

In the current study, $14.9 \%$ of the participants were overweight, while $24.9 \%$ were obese. These findings are consistent with the rapid increase in the frequency of overweight and obesity in Egypt's urban areas. ${ }^{17,18}$ The recorded percentages in the present study are higher than previously reported in private schools in Cairo, where $21 \%$ of the children were obese,${ }^{17}$ and much higher than what was recorded in a Sharkia Governorate urban preparatory school where $20 \%$ of the adolescents and $10.7 \%$ of the children were overweight or obese. ${ }^{18}$

In the current work, the highest percentage of overweight/obese children was found in children aged 3-4 years: $51.4 \%$ of the subjects in this age group were overweight/obese. The percentage decreased to $44.4 \%$ in children aged 5-9 years and decreased in adolescents to $31.2 \%$. These results are higher than what was recorded by WHO in Egypt in 2016, when the percentage of overweight/obese children aged 5-9 years was $40.2 \%$, while overweight/obese adolescents amounted to $34.7 \%{ }^{4}$. This could be ascribed to differences in the body weight curves used, or may represent an increase in the rate of overweight and obesity in 1 year.

Boys were found to have higher overweight/obesity percentage than girls, with a positive correlation between male gender and overweight/obesity. This finding is partially concomitant with the results of a Nigerian study in which males had higher BMI values during early childhood, whereas the reverse was true throughout adolescence. ${ }^{19}$ A significant gender difference was also recorded in a study carried out in Greece, where males were more overweight and obese compared to females. ${ }^{20}$ Differences in BMI between genders in early childhood and throughout adolescence may be due to growth spurts and the development of secondary sexual characteristics of each sex. ${ }^{19}$

No correlation existed between parental education levels and the prevalence of overweight/obesity among children and adolescents. These results are in disagreement with some studies in developing countries, where parental education was inversely correlated with the rates of overweight/obesity. In some cultures, this might be due 
to a belief that overweight children are healthier than normal-weight children. ${ }^{21}$ On the other hand, it has been found that obesity was positively correlated with parental education levels as a result of wealthy parental lifestyles. ${ }^{22}$

The children and adolescents with low SES had the highest percentages of overweight/obesity in the current study. We found no correlation between SES and the prevalence of overweight/obesity. An unhealthy diet and a desk-bound lifestyle are the main causes of overweight and obesity, rather than SES. These findings differ from a study stating that a family's socioeconomic status has an impact on stable household habits, dietary values and physical activity. ${ }^{23}$

In the current work, the solitary dietary element that revealed a positive correlation with overweight/obesity among children and adolescences was carbonated soft drinks. After adjusting for the effects of age and gender, many elements were found to have an impact on overweight/obesity, including carbohydrates, eggs, sugar (either added by the consumer to drinks and food or eaten on its own), crackers, junk food, chocolate, carbonated soft drinks and juices.

Carbohydrates, particularly bread, are the main component in most Egyptian meals. In Egypt, food is eaten with bread, rather than bread with food. ${ }^{24,25}$ This is confirmed in our study, in which $94 \%$ of the participants consumed carbohydrates 1-6 times per day (Table 2). In the current study, solid carbohydrates had an impact on the predominance of overweight/obesity in children and adolescents, although no correlation existed. The lack of correlation contradicts Papandreou et al., who reported a statistically significant positive correlation between obesity and carbohydrate intake. ${ }^{26}$ Furthermore, our results are in disagreement with a recent systematic review suggesting that a high-carbohydrate diet does not increase obesity levels. ${ }^{27}$

There is a strong evidence that increasing the intake of free sugars (defined as sugars added to foods by the manufacturers or consumers) reduces the intake of healthy food, causing overweight and obesity. ${ }^{28}$ In Egypt, sugar consumption increased significantly from $27 \mathrm{~kg} /$ capita in 2000 to $34 \mathrm{~kg} /$ capita in $2015 .{ }^{29}$ Egyptians add 2-3 spoons of sugar to each drink and use it as a dessert instead of fruits, especially in low SES households. Concomitantly, in the present study, sugar (either added by the consumer to drinks and food or eaten on its own) affected the rate of overweight/obesity among Egyptian children and adolescents $(p=0.010)$. Moreover, juices (citric, fresh, canned) significantly affected overweight/obesity $(p=0.045)$. It has been reported that sugar-sweetened beverages (SSBs), which are dense in energy and poor in nutrients, do not induce satiety to the same extent as solid carbohydrates. ${ }^{30}$

In the present work, more than $23 \%$ of the participants consumed carbonated soft drinks 1-6 times daily, which has contributed significantly to the development of over- weight/obesity among Egyptian children and adolescents ( $p=0.001)$. It is worth mentioning that the industry producing carbonated soft drinks in Egypt is very strong and has influential marketing and advocacy campaigns, reflected in the high daily consumption (1.1-1.5 cans per day during 2009-2013)11, the highest sugar consumption among all SSBs. ${ }^{31}$ Notably, there is a consistent link between high levels of soft drink consumption and increases in the intake of sugars and total energy. ${ }^{32}$

In the current study, eggs were among the food items that were associated with overweight/obesity among Egyptian children and adolescents. Categorizing eggs among healthy food is dialectical as a result of their cholesterol content. ${ }^{33}$ In literature, eggs have been recognized among the components of diets associated with the risk of developing overweight and obesity ${ }^{34}$. In contrast, other researchers have identified eggs as part of a healthy diet. $^{35}$

Similarly, chocolate has been blamed for causing weight gain. Chocolates, especially milk and white chocolate, are rich in fat and added sugars. ${ }^{36}$ In contrast, there is evidence that chocolate can be used to reduce body weight. ${ }^{37}$ In the current work, chocolate had an impact on the incidence of overweight/obesity in children and adolescents $(p=0.007)$.

Fruits and vegetables were inversely correlated with overweight/obesity in the present study, but did not reach the level of significance $(r h o=-0.1 ; p=0.062$ ). The fiber existing in fruits and vegetables decreases overweight through different mechanisms, enhancing satiety, decreasing energy intake and suppressing blood glucose levels. Increasing dietary fiber intake could decrease the consumption of other foods high in energy. ${ }^{38}$

Moreover, in the present work junk food was very close to a significant correlation level with BMI $(p \sim 0.062)$ and proved to affect overweight/obesity $(p=0.003)$ after adjusting the effect of age and gender. Fast-food consumption was associated with abdominal obesity in Iranian students based on waist-hip ratios, but was not correlated to general obesity based on BMI. ${ }^{39}$ There are low amounts of micronutrients and fiber in junk food and high amounts of fats and sugars that could be more energetic than the daily energy requirements. ${ }^{40}$

A significant limitation in the current study is the small and convenient sample of subjects, comprised of children attending a free dental clinic and private child nurseries in Greater Cairo. Potentially, the children with a low SES background differ from their companions in rural upper Egypt, which might lead to a degree of bias in the sample. Additionally, a lack of assessment of physical activity, which is an important risk factor for the development of overweight and obesity, as well as the large age range in the adolescent group are among the limitations in the present work. Further studies in which the adolescent group is split into more specific age ranges need to be conducted. 


\section{Conclusions}

It can be concluded that Egyptian children and adolescents suffer from high percentages of overweight and obesity. Among the 14 dietary elements studied, carbonated soft drinks were strongly positively correlated with overweight/obesity among Egyptian children and adolescents. Moreover, after adjusting for the effect of age and gender, carbonated soft drinks, sugar (either added by the consumer to drinks and food or eaten on its own), crackers, juices and chocolates revealed a significant effect on the rate of overweight/obesity. This result is a key message for the Egyptian government to ban carbonated soft drinks and unhealthy food items in schools, as well as to pass legislation to increase the taxes on them to alleviate their conspicuous effect on the health status of Egyptian children and adolescents.

\section{ORCID iD}

Ayoub Al Jawaldeh (D) https://orcid.org/0000-0001-7387-8277 Israa Ahmed Radwan (D) https://orcid.org/0000-0001-8262-5941 Dina Rady (1) https://orcid.org/0000-0002-9672-6935

Sara El Moshy (i) https://orcid.org/0000-0002-2860-8523

Nermeen Abu Bakr (D) https://orcid.org/0000-0003-2962-0070

Marwa Magdy Saad Abbass (D) https://orcid.org/0000-0002-6455-7516

\section{References}

1. GBD 2015 Causes of Death Collaborators. Health effects of overweight and obesity in 195 countries over 25 years. N Eng J Med. 2017;377:13-27. doi:10.1056/NEJMoa1614362

2. Unicef, World Health Organization, World Bank Group Joint Child Malnutrition Estimates. Levels and trends in child malnutrition: 2018 edition. https://reliefweb.int/report/world/levels-and-trendschild-malnutrition-unicefwhoworld-bank-group-joint-child-malnutrition. Published on May 11, 2018. Accessed on April 10, 2020.

3. World Health Organization. Obesity and overweight. https://www .who.int/news-room/fact-sheets/detail/obesity-and-overweight. Updated on March 3, 2020. Accessed on April 10, 2020.

4. World Health Organization. Global Health Observatory data repository. http://apps.who.int/gho/data/node.main. Accessed on April 10, 2020.

5. Reilly JJ, Kelly J. Long-term impact of overweight and obesity in childhood and adolescence on morbidity and premature mortality in adulthood: Systematic review. Int J Obes (Lond). 2011;35(7):891-898. doi:10.1038/ijo.2010.222

6. Bonell C, Jamal F, Harden A, et al. Systematic review of the effects of schools and school environment interventions on health: Evidence mapping and synthesis. Public Health Res. 2013;1(1). doi:10.3310 /phr01010

7. Musaiger AO. Food Consumption Patterns in the Eastern Mediterranean Region. Manama, Bahrain: Arab Center for Nutrition; 2011. https://www.researchgate.net/publication/236668592_Food_ Consumption_Patterns_in_the_Eastern_Mediterranean_Region. Accessed on April 10, 2020.

8. Fanzo J, Hawkes C, Udomkesmalee E, Afshin A, et al. Global Nutrition Report: Shining a Light to Spur Action on Nutrition. Bristol, United Kingdom: Development Initiatives Poverty Research; 2018. https:// scalingupnutrition.org/news/the-2018-global-nutrition-report-shining-a-light-to-spur-action-on-nutrition/. Accessed on April 10, 2020.

9. Food and Agriculture Organization of the United Nations. FAOSTAT - new food balances. http://www.fao.org/faostat/en/\#data/ FBS. Accessed on April 10, 2020.

10. World Health Organization. Diet, Nutrition, and the Prevention of Chronic Diseases: Report of a Joint WHO/FAO Expert Consultation. Geneva, Switzerland: World Health Organization; 2003. https:// www.who.int/dietphysicalactivity/publications/trs916/download /en/. Accessed on April 10, 2020.

11. Yang $L$, Bovet $P$, Liu $Y$, et al. Consumption of carbonated soft drinks among young adolescents aged 12 to 15 years in 53 low-and middle-income countries. Am J Public Health. 2017;107(7):1095-1100. doi:10.2105/AJPH.2017.303762

12. Daniel WW, Cross CL. Biostatistics: A Foundation for Analysis in the Health Sciences. $11^{\text {th }}$ ed. Hoboken, NJ: Wiley; 2018.

13. World Health Organization. Growth reference 5-19 years. https: //www.who.int/growthref/who2007_bmi_for_age/en/. Accessed on April 10, 2020.

14. Kuźbicka K, Rachoń D. Bad eating habits as the main cause of obesity among children. Pediatr Endocrinol Diabetes Metab. 2013;19(3):106-110.

15. El-Gilany A, El-Wehady A, El-Wasify M. Updating and validation of the socioeconomic status scale for health research in Egypt. East Mediterr Health J. 2012;18(9):962-968. http://applications.emro .who.int/emhj/v18/09/2012_18_9_0962_0968.pdf. Accessed on April 10, 2020.

16. Agostoni C, Braegger C, Decsi T, et al.; ESPGHAN Committee on Nutrition. Role of dietary factors and food habits in the development of childhood obesity: A commentary by the ESPGHAN Committee on Nutrition. J Paediatr Gastroenterology Nutr. 2011;52(6):662-669. doi:10.1097/MPG.0b013e3182169253

17. Hafez AS, EL Amady MY, Hassan NE. Obesity profile among primary school children in Cairo. Egypt J Community Med. 2004;18:99-170.

18. Talat MA, El Shahat E. Prevalence of overweight and obesity among preparatory school adolescents in Urban Sharkia Governorate, Egypt. Gaz Egypt Paediatr Assoc. 2016;64:20-25. doi:10.1016 /j.epag.2015.11.004

19. Dietz WH. Overweight in childhood and adolescence. N Engl J Med. 26;350(9):855-857. doi:10.1056/NEJMp048008

20. Maruf FA, Aronu UC, Chukwuegbu K, Aronu AE. Influence of gender on prevalence of overweight and obesity in Nigerian schoolchildren and adolescents. Tanzan J Health Res. 2013;15(4):247-251. doi:10.4314/thrb.v15i4.6

21. Krassas GE, Tsametis C, Baleki V, et al; Balkan Group for the Study of Obesity. Prevalence of overweight and obesity among children and adolescents in Thessaloniki - Greece and Kayseri - Turkey. Pediatr Endocrinol Rev. 2004;1(Suppl 3):460-464.

22. Thibault H, Contrand B, Saubusse E, Baine M, Maurice-Tison S. Risk factors for overweight and obesity in French adolescents: Physical activity, sedentary behavior and parental characteristics. Nutrition. 2010;26(2):192-200. doi:10.1016/j.nut.2009.03.015

23. Andegiorgish AK, Wang J, Zhang X, Liu X, Zhu H. Prevalence of overweight and obesity, associated risk factors among school children and adolescents in Tianjin, China. Eur J Pediatr. 2012;171(4):697-703. doi:10.1007/s00431-011-1636-x

24. El-Bayoumy I. Prevalence of obesity among adolescents (10-14 years) in Kuwait. Diabetes Metab Res Rev. 2012;28.

25. Hassan-Wassef $\mathrm{H}$. Food habits of the Egyptians: Newly emerging trends. East Mediterr Health J. 2004;10(6):898-915. https://apps.who. int/iris/handle/10665/116908. Accessed on April 10, 2020.

26. Abdel-Hady D, El-Gilany AH, Sarraf B. Dietary habits of adolescent students in Mansoura, Egypt. Pan Afr Med J. 2012;13:22.

27. Papandreou D, Makedou K, Zormpa A, Karampola M, loannou A, Hitoglou-Makedou A. Are dietary intakes related to obesity in children? Open Access Maced J Med Sci. 2016;4(2):194-199. doi:10.3889 /oamjms.2016.045

28. Sartorius K, Sartorius B, Madiba TE, Stefan C.Doeshigh-carbohydrate intake lead to increased risk of obesity? A systematic review and meta-analysis. BMJ Open. 2018;8(2):e018449. doi:10.1136/bmjopen -2017-018449

29. Malik VS, Pan A, Willett WC, Hu FB. Sugar-sweetened beverages and weight gain in children and adults: A systematic review and meta-analysis. Am J Clin Nutr. 2013;98(4):1084-1102. doi:10.3945 /ajcn.113.058362

30. Bader Esam A. Economic modelling and forecasting of sugar production and consumption in Egypt. Int J of Agric Econ. 2017;2(4):96-109. doi:10.11648/j.ijae.20170204.12

31. van Dam RM, Seidell JC. Carbohydrate intake and obesity. Eur J Clin Nutr. 2007;61(Suppl 1):S75-99. doi:10.1038/sj.ejcn.1602939 
32. Garnett BR, Rosenberg KD, Morris DS. Consumption of soda and other sugar-sweetened beverages by 2-year-olds: Findings from a population-based survey. Public Health Nutr. 2013;16(10):1760-1767. doi:10.1017/S1368980012004399

33. Keller A, Bucher Della Torre S. Sugar-sweetened beverages and obesity among children and adolescents: A review of systematic literature reviews. Child Obes. 2015;11(4):338-346. doi:10.1089 /chi.2014.0117

34. Fernandez ML. Rethinking dietary cholesterol. Curr Opin Clin Nutr Metab Care. 2012;15(2):117-121. doi:10.1097/MCO.0b013e32834d2259

35. Flores $M$, Macias N, Rivera $M$, et al. Dietary patterns in Mexican adults are associated with risk of being overweight or obese. J Nutr. 2010;140(10):1869-1873. doi:10.3945/jn.110.121533

36. Hsiao PY, Mitchell DC, Coffman DL, et al. Dietary patterns and diet quality among diverse older adults: The University of Alabama at Birmingham study of aging. J Nutr Health Aging. 2013;17(1):19-25. doi:10.1007/s12603-012-0082-4

37. Greenberg JA, Manson JE, Buijsse B, et al. Chocolate-candy consumption and 3-year weight gain among postmenopausal US women. Obesity (Silver Spring). 2015;23(3):677-683. doi:10.1002 /oby.20983

38. Dorenkott MR, Griffin LE, Goodrich KM, et al. Oligomeric cocoa procyanidins possess enhanced bioactivity compared to monomeric and polymeric cocoa procyanidins for preventing the development of obesity, insulin resistance, and impaired glucose tolerance during high-fat feeding. J Agric Food Chem. 2014;62(10):2216-2227. doi:10.1021/jf500333y

39. Burton-Freeman B. Dietary fiber and energy regulation. $J$ Nutr. 2000;130(Suppl 2S):272S-275S. doi:10.1093/jn/130.2.272S

40. Mohammadbeigi A, Asgarian A, Moshir E, et al. Fast food consumption and overweight/obesity prevalence in students and its association with general and abdominal obesity. J Prev Med Hygiene. 2018;59(3):E236-E240. doi:10.15167/2421-4248/jpmh2018.59.3.830.

41. Shah T, Purohit G, Nair SP, Patel B, Rawal Y, Shah RM. Assessment of obesity, overweight and its association with the fast food consumption in medical students. J Clin Diagn Res. 2014;8(5):CC05-7. doi:10.7860/JCDR/2014/7908.4351 
